\title{
A Proposal to Support the Valuable Design Method by Redefining Empathetic Design
}

\author{
Lin Zhang ${ }^{1}$, Yancong Liu ${ }^{1}$, Jungpyo Hong ${ }^{2}$ \\ 1.Department of Industrial Design, College of Mechanical and Electronic Engineering, China \\ University of Petroleum, Qingdao, 266580, China \\ 2.Department of Industrial Design, Art School of Chonbuk National University, Jeonju, 561-7656, \\ Korea
}

\begin{abstract}
Empathetic design is considered as a user-centered design approach that pays attention to the user's feelings toward a product [1][2]. But the design process and design factors are not clearly. This paper analyzed the customer needs, emotion and empathy in psychology, restudied the definition and design process of $3 \mathrm{E}$ design(emotional design, empathic design and empathetic design) as well; then proposed the design's keywords and new process of empathetic design for making it to be used widely.

\section{Introduction}

How is the era developed and what is come to bat the design? Here just take the cellphone as an example to explain.

The cellphone could beconsidered as the most important invention at last century. In 1970 Amos E. Joel, Jr., a Bell Labs engineer invented an automatic "call handoff" system to allow mobile phones to move through several cell areas during a single conversation without interruption [3]. A cellular telephone switching plan was described by Fluhr and Nussbaum in 1973, and a cellular telephone data signaling system was described in 1977 by Hachenburg et [4]. At the upsurge stage, the concept of mobile phone is small, portable and emphasis on "moving" function.

$2 \mathrm{G}$ mobile phone systems emerged in the 1990s. And along with the convenience of cellular phone was recognized day after day, the people became to pay attention to the diversity of it, and at the same time, the emotional design began to make a fine figure, under the concept from emotional design, multifarious phone about color, shape and function was designed for satisfying customer's need.

3G-technology was amplified in Japan first in 2001, and then spread quickly to South Korea, USA then to the whole world. By the end of 2007, there were 295 million subscribers on 3G networks worldwide, which reflected $9 \%$ of the total worldwide subscriber base. And the multifarious shape, color is no more the key point for mobile phone; in a contrary, the simple rectangle with more intangible contents (applications) and information began to catch the eye of customer.

Actually, this change shows designers a new challenge about how to shift mental gears to tangible thinking to intangible one, and how could we design for satisfying customer need from intangible aspect? Maybe the original design method should be modified.
\end{abstract}

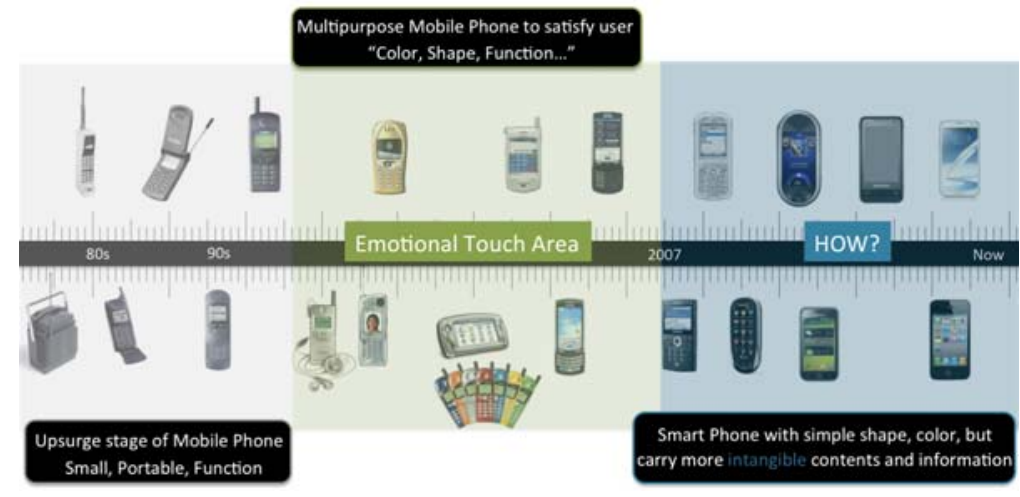

Fig.1. Explanation of Design Changes via Development of Mobile Phones 


\section{Customer Needs}

Based oMaslow's Hierarchy of Needs, the customer needs could be described as following.

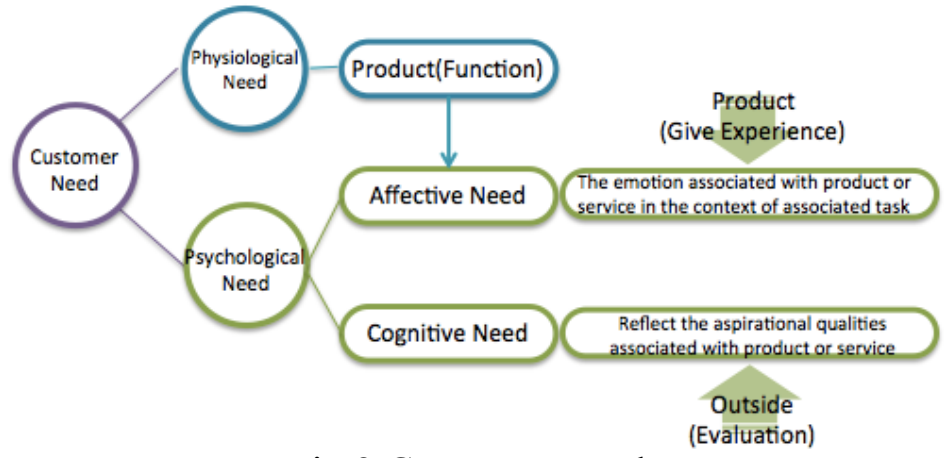

Fig.2.Customer Needs

Whether customer's psychological needs are satisfied or not depends on the product itself attracts the customer or not, the environments that the product used in, and also the behaviors in which customer engages with carrying the product.The psychological needs is considered as relating with emotion and thinking, which has different phenomena. Emotion appears so antithetical to thinking that they are said to interfere with each other. By above viewpoint, there is much evidence that people perceive reality in at least two ways, one is affective (intuitive and experiential) and the other is cognitive (analytical and rational) for us to understand customers'psychological needs from two aspects: affective need and cognitive need [5].

Customers' Psychological Needs:

Affective Need

The emotion associated with product or service in the context of associated task; in other words, here the affective needs is satisfied through the experience process of using the product.

Cognitive Need

Reflect the aspirational qualities associated with product or service. There is many factors influence it, such as: knowledge, background, and living environment. Cognitive need could effect on the affective need, but slowly, only after the cognitive need achieving to a fairly high level, the affective need orientation is changed by inches.

\section{Restudy of 3E Design}

Emotional design, Empathic design and Empathetic design are 3-design forms that consider customer's feeling inthe design process and design result.

\subsection{Emotion and Empathy}

Comparing "emotion" with "empathy" in Psychology,emotion is a response to stimulus and it includes cognitive appraisal, bodily symptoms, action tendencies, expression and feelings; empathy is considered as a capability, which could recognize feeling that are being experienced not only by own self but also another sentient or semi-sentient [6]. For example, emotion is characterized by bodily feelings, and then grasping the bodily feelings of another will be central to empathy. The ability to imagine oneself as another person is a sophisticated imaginative process. However, the basic capacity to recognize emotions is probably innate [7] and may be achieved unconsciously. Yet it can be trained [8] and achieved with various degrees of intensity or accuracy.

Empathy could be distinguished to two components: affective and cognitive. The affective element is seen as an immediate emotional response of the empathizer to the affective state of the empathee [9].This emotional response can have several forms, of which congruence or emotional contagion (e.g. automatically responding with a smile and feeling happy when you see somebody smile at you) is the most common form [10]. Mead added the cognitive element: the understanding by the observer of the other person's feelings [11]. And suggested the perspective taking can facilitate one's ability to understand another person's affective behavior and understand how another person views the world. 


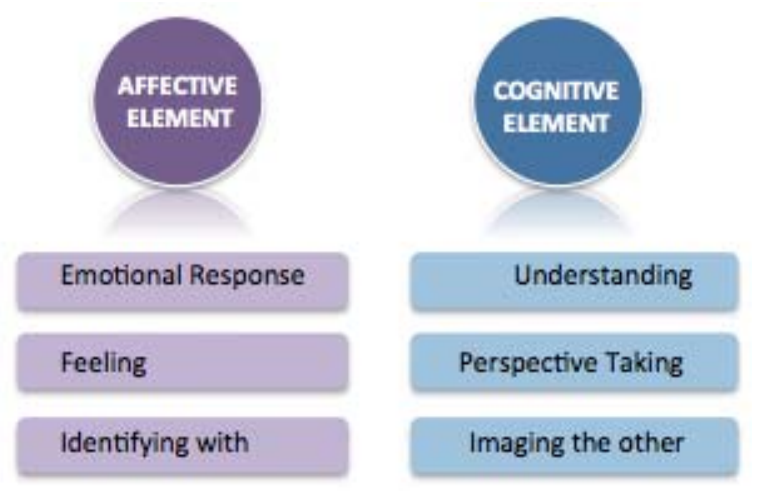

\subsection{Emotional Design}

Fig.3. Affective and Cognitive Elements of Empathy

In the restudy, analyzed the 73 definitions that collected about emotional design, the quiddity of emotional design could be summarized as "The Emotion are Expressed through Tangible Product". The design process, design applied area and design method was researched in the Preceding research.
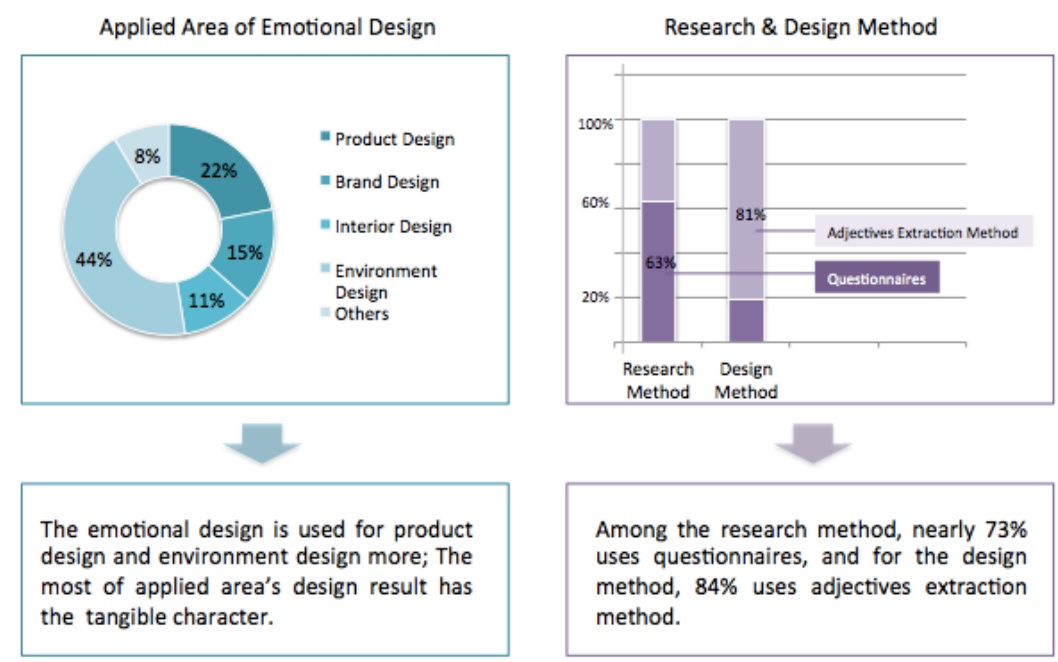

Fig.4. Preceding Research Result of Emotional Design

\subsection{Empathetic Design \& Empathic Design}

Empathic design and empathetic design are two models in need of a clear classification to help to eliminate design models whose definition have never been formalized and also can be a source of confusion and misinformation [12]. So here will try to classify the two design models through the definition and processcomparing.

The empathic design is used widely inthe management department as the emotional design in the design area.Empathetic design has no clear definition and design process until now, the only usefulinformation we know about the empathetic design is the words from Latanya Sweeney,the Professor of Government and Technology in Residence at Harvard University,"Empathetic design is that designer should actually spend a day living as the user", which means the experience for designer to be as a user is very important.

Nearly 100papers about empathetic design were collected first, after simpledifferentiating with the above sentences as reference, no more than 30 papers couldbe recognized having the empathetic thinking in them. And then these papers areclassified according to two big items: research area and research method. Amongthese 30 papers, only 4 could be considered as the valuable resource forunderstanding empathetic design in detail, and get idea for reconstructing thedefinition and design process of empathetic design. 


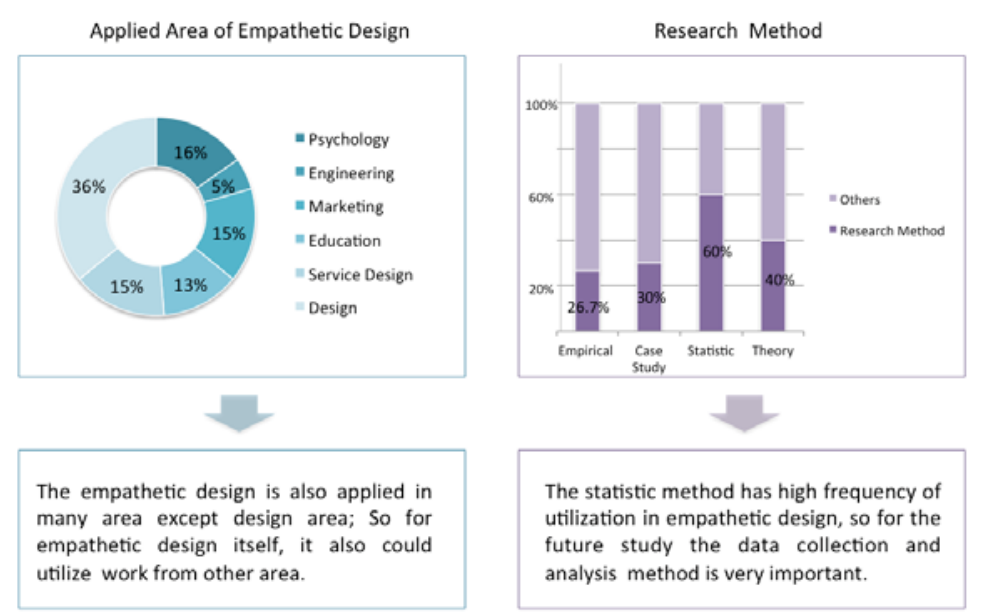

\section{Elements Extraction of Empathetic Design}

Fig.5. Preceding Research Result of Empathetic Design

The $3 \mathrm{E}$ design has the same design goal (satisfy customer needs in order to create products), but different detail method.

Emotional design has the normal design process and the most frequently method to be used is questionnaires and adjective words extraction; the process of empathic design has been put forward as the five key steps by Leonard and Rayport : "Observation, Capturing Data, Reflection and Analysis, Brainstorming for solutions, Developing prototypes of possible solutions", empathetic design has no design process now.

In emotional design designer's will takes mastery, so it's very difficult to touch the customer need, especially the deep need; so does the empathic design, the customer need could not be satisfied by relying on observing the customer's behavior and action only. Empathetic design is different, by empathy transferring and experience of designer to be as user, designer could understand user's situation and need well, but not easily (the different living environment, education background, social position affect on it). With the help of UCD, emotional design, empathic design, empathy, the important elements of empathetic design were extracted.
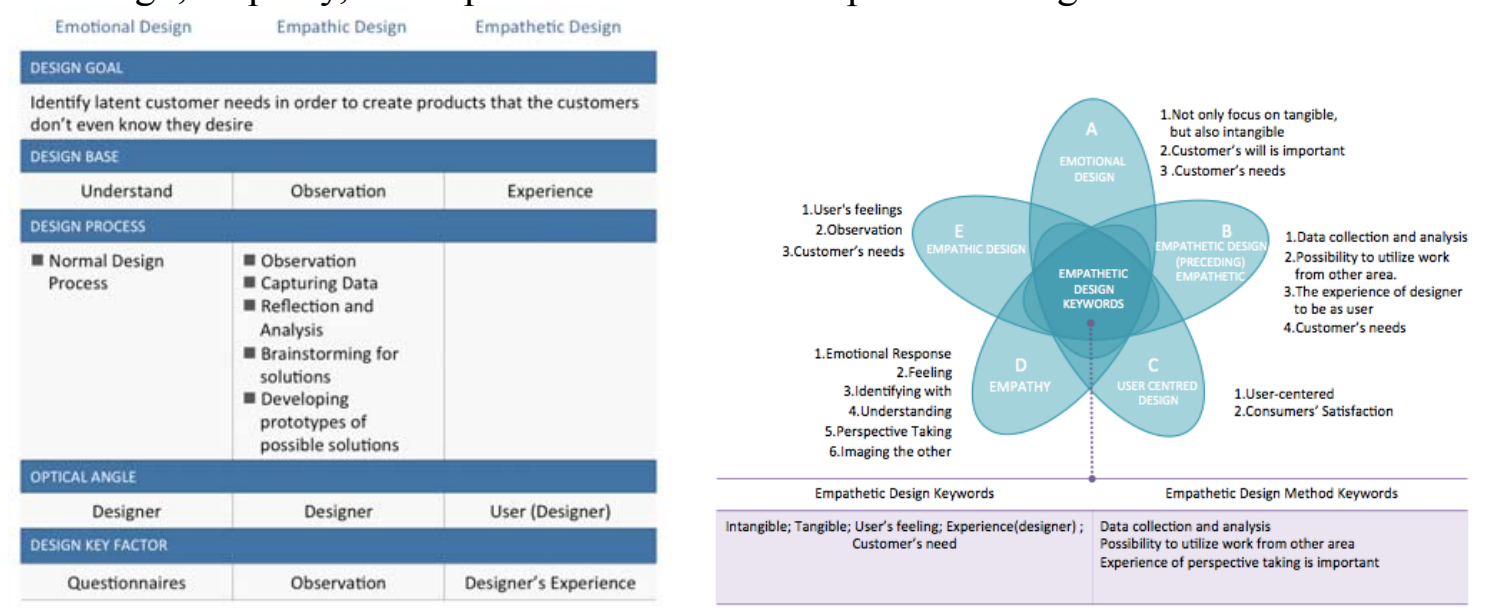

Fig.6. Emotional Design \& Empathic Design \& Empathetic DesignFig.7. Extraction of Empathetic

\section{Conclusions And Future Study}

Design Keyword

The keywords of Empathetic Design were extracted through studying customer need and comparing 3E Design. The keywords that extracted for empathetic design are: intangible, tangible, user's feeling, experience, customer's need; and the design method keyword extracted are: Data collection and analysis; possibility to utilize work from other areas, and the last one is "experience of perspective taking is important".

In the future study, the meaning of each keyword will be analyzed and the definition and design process of Empathetic Design will be summarized. 


\section{Acknowledgements}

This research gets support from: Qingdao Applied Basic Research Project for Youth (14-2-4-54-jch) and Project "Key Technology and Application Demonstration of Manufacturing Service about Packaging and Printing Equipment" from Meiguang Machinery Ltd. Qingdao.

\section{Reference}

[1] Fulton-Suri (2003). Mad Dogs, Dreamers and Sages: Growth in the Age of Ideas. Elounda Press. ISBN 978-0-9744073-0-2.

[2] L. Crossley. "Building Emotions in Design". The Design Journal 6 (3): 35-45.

[3] History of Mobile Phone, http://en.wikipedia.org/wiki/History_of_mobile_phones

[4]Z. Fluhr and E. Nussbaum, "Switching Plan for a Cellular Mobile Telephone System:, IEEE Transactions on Communications volume 21, 1973, p11. 1281

[5]Summarized from H.M. Khalid and M. G. Helander, Customer Emotional Needs in Product Design, Concurrent Engineering, 2006

[6] Empathy, http://en.wikipedia.org/wiki/Empathy

[7]Happiness Genes: Unlock the Positive Potential Hidden in Your DNA, New Page Books, 2010 ISBN 978-1-60163-105-3

[8] O'Malley, W. J., 1999. Teaching Empathy, America, 180(12), 22-26.

[9] Merlijn Kouprie and Froukje Sleeswijk Visser, A framework for empathy in design: stepping into and out of the user's life, Journal of Engineering Design,Vol. 20, No. 5, October 2009, P437-448

[10] Gladstein 1983, cited in Duan and Hill 1996, Vreeke and van der Mark 2003 [11]Baron-Cohen and Wheelwright 2004

[12]Peter Landwehr, Empathic Design vs Empathetic Design: A History of Confusion, November, 2007 